\title{
Self-assembled rosette nanotubes for incorporating hydrophobic drugs in physiological environments
}

This article was published in the following Dove Press journal:

International Journal of Nanomedicine

7 January 2011

Number of times this article has been viewed

\author{
Shang Song' \\ Yupeng Chen ${ }^{1,2}$ \\ Zhimin Yan ${ }^{4}$ \\ Hicham Fenniri ${ }^{4}$ \\ Thomas J Webster ${ }^{1,3}$ \\ 'School of Engineering, ${ }^{2}$ Department \\ of Chemistry, ${ }^{3}$ Department of \\ Orthopaedics, Brown University, \\ Providence, RI, USA; ${ }^{4}$ National Institute \\ for Nanotechnology and Department \\ of Chemistry, National Research \\ Council and University of Alberta, \\ Edmonton, Canada
}

\begin{abstract}
Rosette nanotubes (RNTs) are novel, biomimetic, injectable, self-assembled nanomaterials. In previous studies, materials coated with RNTs have significantly increased cell growth (eg, osteoblasts, chondrocytes, and endothelial cells) due to the favorable cellular environment created by RNTs. It has also been suggested that the tubular RNT structures formed by base stacking and hydrophobic interactions can be used for drug delivery, and this possibility has not been studied to date. Here we investigated methods to load and deliver tamoxifen (TAM, a hydrophobic anticancer drug) using two different types of RNTs: single-base RNTs and twin-base RNTs. Drug-loaded RNTs were characterized by nuclear magnetic resonance spectroscopy, diffusion-ordered nuclear magnetic resonance spectroscopy (DOSY NMR), and ultraviolet-visible (UV-Vis) spectroscopy at different ratios of twin-base RNTs to TAM. The results demonstrated successful incorporation of hydrophobic TAM into RNTs. Importantly, because of the hydrophilicity of the outer surface of the RNTs, TAM-loaded RNTs were dissolved in water, and thus have great potential to deliver hydrophobic drugs in various physiological environments. The results also showed that twin-base RNTs further improved TAM loading. Therefore, this study demonstrated that hydrophobic pharmaceutical agents (such as TAM), once considered hard to deliver, can be easily incorporated into RNTs for anticancer treatment purposes.
\end{abstract}

Keywords: drug delivery, rosette nanotubes, self-assembly, tamoxifen

\section{Introduction}

There has been increasing interest in the use of injectable, biocompatible, biodegradable polymers ${ }^{1-5}$ and nanoparticles ${ }^{6}$ for anticancer drug delivery applications. Methods based on external stimuli (ie, ultraviolet light for crosslinking) to create amphiphilic polymers ${ }^{7}$ or lipid drug mixtures ${ }^{6}$ to deliver water-insoluble anticancer drugs seek to improve drug solubility in water, increase drug bioavailability, and decrease drug toxicity. ${ }^{8}$ In addition, molecules with self-assembly properties have been studied for such applications. ${ }^{9-11}$ However, complex, chemical treatments used to create some of these drug carriers can result in a reduction of drug efficacy. ${ }^{12,13}$ Also, many simpler mixtures provide a fast, uneven release of hydrophobic drugs under physiological conditions, thus limiting prolonged cell-drug interactions. ${ }^{14,15}$

In order to avoid such ineffective, complex drug carrier designs, and ensure solubility of water-insoluble drugs, rosette nanotubes (RNTs) have been developed and have shown to be advantageous in regenerative medicine due to their biologicallyderived structure and chemical properties. RNTs are novel, biomimetic, synthetic, 
self-assembled nanomaterials. Structurally, RNTs have hollow channels that can be used for drug encapsulation. To date, there have been two types of RNTs, ie, single-base RNTs such as K1 (K=lysine; Figure 1) and twin-base RNTs such as twin-base linker molecules (TBLs) (Figure 2). Both types of RNTs are composed of self-assembled supramolecular structures, the basic building blocks of which are guanine $(\mathrm{G})$ and cytosine $(\mathrm{C})$ DNA base pairs. ${ }^{16-19}$ The $\mathrm{G} \wedge \mathrm{C}$ heteroaromatic bicyclic base of RNTs possess the WatsonCrick donor-donor-acceptor of guanine and the acceptoracceptor-donor of cytosine. For $\mathrm{K} 1, \mathrm{G} \wedge \mathrm{C}$ undergoes a hierarchical self-assembly process under physiological conditions to form a six-member rosette (ie, supermacrocycle) by the formation of 18 hydrogen bonds. A lysine side chain is used for solubility, biocompatibility, and for imposing supramolecular chirality. In the case of TBL, two covalently connected $\mathrm{G} \wedge \mathrm{C}$ bases self-assemble into a 6-member twin rosette maintained by 36 hydrogen bonds. For both types of RNTs, the rosettes form a stable stack with an inner diameter of $11 \AA$ due to dispersion forces, base stacking interactions, and hydrophobic effects. The outer diameters for K1 and TBL are $3.5 \mathrm{~nm}$ and $3.8 \mathrm{~nm}$, respectively (Figures 1 and 2, respectively).

RNTs may be able to deliver hydrophobic drugs for a number of reasons. The self-assembly of RNTs creates a hydrophobic core and hydrophilic outer surface. Thus, RNTs are able to incorporate water-insoluble drugs into their tubular structures by hydrophobic interactions with the core whereas their hydrophilic outer surface can shield such hydrophobic drugs in a physiological environment for subsequent prolonged release (even into the cell). RNTs
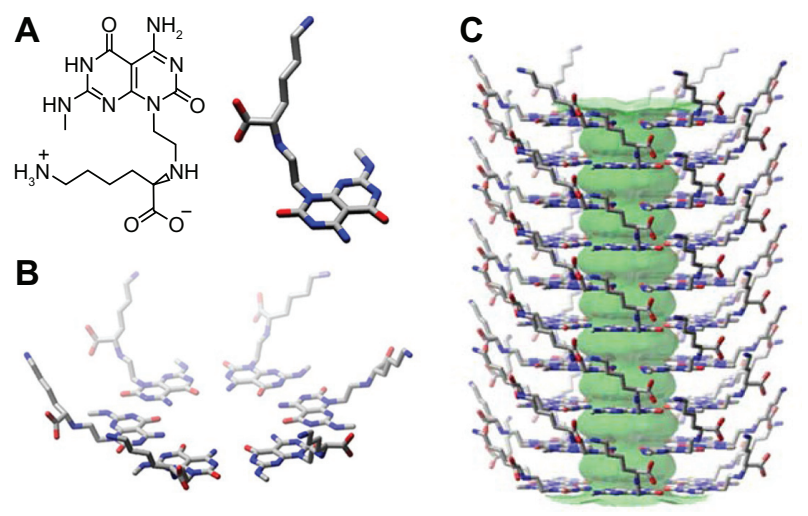

Figure I Schematic illustration of the hierarchical assembly of $\mathrm{KI}$ with a lysine side chain. A) The $\mathrm{G} \wedge \mathrm{C}$ motif functionalized with a lysine side chain. B) Six $\mathrm{G} \wedge \mathrm{C}$ motifs self-assemble into a rosette supermacrocycle by the formation of 18 hydrogen bonds, and C) The rosettes stack up to form a stable $3.5 \mathrm{~nm}$ diameter RNT with an II $\AA$ inner channel.

Abbreviations: C, cytosine; G, guanine; K, lysene; RNT, rosette nanotubes.

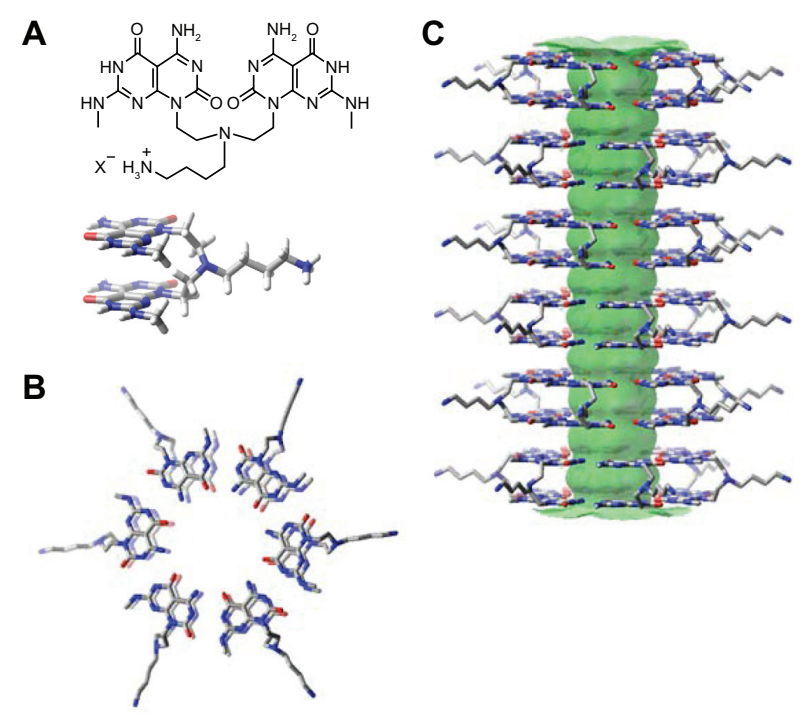

Figure 2 Schematic illustration of the hierarchical assembly of TBLs. A) The twin $\mathrm{G} \wedge \mathrm{C}$ motif functionalized with an aminobutyl group. B) Six twin $\mathrm{G} \wedge \mathrm{C}$ motifs selfassemble into a twin rosette supermacrocycle held by the formation of 36 hydrogen bonds. C) The rosettes stack up to form a stable $3.8 \mathrm{~nm}$ diameter TBL with an II Å inner channel.

Abbreviations: TAM-KI, tamoxifen encapsulated in $\mathrm{KI}$; TAM-TBL, tamoxifen encapsulated in TBL.

could also be chemically functionalized with peptides to deliver growth factors for healthy tissue regeneration after the delivery of drugs to kill cancer cells. For example, previous studies have shown that hydrogels coated with Arg-Gly-Asp-Ser-Lys modified RNTs improved osteoblast growth compared with unmodified hydrogels, thus making them attractive to potentially regenerate healthy bone in osteosarcoma patients..$^{20}$ It has also been shown that RNTs are biocompatible and are able to enhance protein adsorption, cell adhesion, and subsequent cell functions. ${ }^{16,20,21}$ Thus, it is conceivable that the RNTs could not only improve healthy cell and tissue growth, but may also deliver hydrophobic drugs to target areas.

Due to its hydrophobic properties and delivery problems, the drug selected for this study was tamoxifen (TAM), a waterinsoluble anticancer drug used in the treatment of patients with estrogen receptor-positive breast cancer. ${ }^{22}$ In this study, TAM was incorporated into two types of RNTs, ie, K1 and TBL. Successful incorporation was verified using diffusion-ordered nuclear magnetic resonance spectroscopy (DOSY NMR) and ultraviolet-visible (UV-Vis) spectroscopy. Subsequent comparison between the two types of RNTs showed that the more stable TBL enabled more TAM loading. Therefore, this study demonstrated that RNTs are potential drug delivery devices for water-insoluble drugs, such as TAM, and should be further studied as anticancer coatings on medical devices or as stand-alone injectable anticancer drugs. 


\section{Materials and methods \\ Preparation of KI and TBL}

$\mathrm{K} 1^{18}$ (RNT with a lysine side chain) and TBL ${ }^{19}$ were synthesized according to previously reported procedures.

\section{Characterization of TAM-loaded $\mathrm{KI}$ and TBL}

$\mathrm{K} 1$ building block $(4.30 \mathrm{mg})$ was first dissolved in deuterated methanol $\left(\mathrm{CD}_{3} \mathrm{OD}, 1 \mathrm{~mL}\right)$ and aged for 1 day. $t-\mathrm{BuOH}(3 \mu \mathrm{L})$ ( $\geq 99.5 \%$, anhydrous; Sigma-Aldrich, St Louis, MO) was added as an internal standard to quantify, by ${ }^{1} \mathrm{H}-\mathrm{NMR}$, the extent of TAM (T5648; Sigma) association with the RNTs. TAM ( $5 \mathrm{mg}$ ) was then added, thus resulting in a solution with a 5:3 TAM:K1 molar ratio. The solution was aged for two days to allow for the drug-loading process, and the supernatant was isolated for subsequent ${ }^{1} \mathrm{H}-\mathrm{NMR}$ studies. Other solutions with 5:1 and 5:5 TAM:K1 molar ratios were also prepared. The TBL building block ( $3 \mathrm{mg}$ ) was dissolved in $\mathrm{CD}_{3} \mathrm{OD}(1 \mathrm{~mL})$ and the same procedure was followed to prepare mixtures with TAM $(1.53 \mathrm{mg})$ resulting in a solution with a 5:5 molar ratio of TAM:TBL.

The supernatants were characterized by DOSY NMR and UV-Vis. ${ }^{1} \mathrm{H}-\mathrm{NMR}$ was used to observe the amount of drug loaded into the RNTs at various time points. All the NMR experiments were conducted on a Varian Direct Drive $600 \mathrm{MHz}$ spectrometer with a dual broadband probe. UV-vis spectra were recorded on an Agilent 8453. After this series of spectral analyses was completed, $\mathrm{CD}_{3} \mathrm{OD}$ was evaporated using a stream of nitrogen and replaced with the same volume of deuterated water $\left(\mathrm{D}_{2} \mathrm{O}\right)$. Any hydrophobic TAM that was not incorporated into the nanotubes precipitated in $\mathrm{D}_{2} \mathrm{O}$ and was filtered out prior to NMR studies.

The NMR peaks corresponding to the drug were monitored and their integration was compared to the internal standard to determine the amount of encapsulated versus free drug in $\mathrm{CD}_{3} \mathrm{OD}$. Under the same experimental conditions, DOSY NMR was performed to detect subtle changes in the diffusion coefficients of TAM in the presence of $\mathrm{K} 1$ and TBL.

For UV-Vis experiments, the supernatants of the drugloaded $\mathrm{K} 1$ and TBL were diluted with methanol to a final concentration of $25 \mu \mathrm{g} / \mathrm{mL}$ of TAM. In addition, three other solutions were prepared, ie, $5 \mu \mathrm{g} / \mathrm{mL}$ TAM, $25 \mu \mathrm{g} / \mathrm{mL} \mathrm{K1}$, and $25 \mu \mathrm{g} / \mathrm{mL}$ TBL. Each solution $(3 \mathrm{~mL})$ was placed in a $1 \mathrm{~cm} \times 1 \mathrm{~cm}$ cuvette for UV-Vis experiments. In another series of experiments the solutions were prepared at the same concentration in $\mathrm{D}_{2} \mathrm{O}$ and analyzed by UV-Vis spectroscopy. Because TAM was insoluble in $\mathrm{D}_{2} \mathrm{O}$, no corresponding
Table I 'H-NMR spectroscopy of TAM-KI mixture (5:3 molar ratio) at different time intervals monitored at $7.25 \mathrm{ppm}$

\begin{tabular}{lllllllll}
\hline Time (h) & $\mathbf{0}$ & $\mathbf{I}$ & $\mathbf{2}$ & $\mathbf{3}$ & $\mathbf{4}$ & $\mathbf{5}$ & $\mathbf{2 4}$ & $\mathbf{4 8}$ \\
\hline 'H integration & 2.20 & 2.18 & 2.09 & 2.07 & 2.02 & 2.0 & 1.69 & I.68 \\
\hline
\end{tabular}

Abbreviation: TAM-KI, tamoxifen encapsulated in KI.

peak was recorded. Peaks from TAM and TAM-K1 were compared with those from TAM and TAM-TBL.

\section{Sample preparation of TAM-loaded KI and TBL for atomic force microscopy}

For atomic force microscopy (AFM) experiments, samples prepared in $\mathrm{D}_{2} \mathrm{O}$ were diluted to $25 \mu \mathrm{g} / \mathrm{mL}$ and imaged using a MultiMode Nanoscope IV AFM (Digital Instruments/Veeco Instruments, New York, NY) equipped with an E scanner. Height profiles were measured using silicon cantilevers (MikroMasch USA, Inc., Portland, OR) with low spring constants of $4.5 \mathrm{~N} / \mathrm{m}$ in tapping mode. To obtain a clear image of the surface, a low scan rate $(0.5-1 \mathrm{~Hz})$ and amplitude setpoints $(1 \mathrm{~V})$ were chosen during measurements. ${ }^{19} \mathrm{Clean}$ mica substrates (Mica-Grade V-4 SPI, Catalog number 01918-CF and Lot number 1100315) were prepared and the samples were deposited by spin-coating $20 \mu \mathrm{L}$ of each solution at $2000 \mathrm{rpm}$ for 20 seconds.

\section{Statistical analysis}

Data are expressed as standard error of the mean. Statistics were performed using a Student's one-tailed $t$-test, with $P<0.05$ being considered statistically significant.

\section{Results}

Because of their large molecular weight and long relaxation time, $\mathrm{K} 1$ and TBL were not detected by ${ }^{1} \mathrm{H}-\mathrm{NMR}$ spectroscopy. Thus as the drug becomes encapsulated by the RNTs, its integration by ${ }^{1} \mathrm{H}-\mathrm{NMR}$ decreases relative to the internal standard ( $t$-BuOH). At the TAM:K1 molar ratio of 5:3 (Table 1), the incorporation of the drug reached an average maximum of $22 \%$ within one day (ca. $0.254 \mathrm{mg}$ of TAM per $1 \mathrm{mg}$ of K1).

Table 2 'H-NMR spectroscopy of TAM-KI and TAM-TBL at different molar ratios monitored at $2.68-3 \mathrm{PPm}$

\begin{tabular}{lllll}
\hline TAM-KI molar ratio & $\mathbf{( 5 : 1 )}$ & $\mathbf{( 5 : 3 )}$ & $\mathbf{( 5 : 5 )}$ & $\mathbf{( 5 : 5 )}$ \\
\hline $\begin{array}{l}\text { 'H integration of TAM } \\
\text { before encapsulation }\end{array}$ & 0.03 & 2.33 & 2.33 & $\mathrm{I}$ \\
$\begin{array}{l}\text { 'H integration of TAM } \\
\text { after encapsulation }\end{array}$ & 0.02 & 1.85 & 1.72 & 0.72 \\
$\begin{array}{l}\text { Average change } \\
\text { A }\end{array}$ & $2.13 \%$ & $22 \%$ & $26.5 \%$ & $30 \%$ \\
\hline
\end{tabular}

Abbreviations: TAM-KI, tamoxifen encapsulated in KI; TAM-TBL, tamoxifen encapsulated in TBL. 
Table 3 DOSY NMR of TAM and of TAM-KI mixture (5:5 molar ratio)

\begin{tabular}{llllllll}
\hline TAM peaks & Peak I & Peak 2 & Peak 3 & Peak 4 & Peak 5 & Peak 6 & Average \\
\hline Chemical shift $(\mathrm{Ppm})$ & 6.7 & 6.55 & 3.9 & 3.1 & 2.58 & 2.41 & 7 \\
$\begin{array}{l}\text { Diffusion coefficient } \\
\left(\mathrm{m}^{2} / \mathrm{s}\right) \text { before }\end{array}$ & 7.2 & 7.4 & 7.2 & 7.4 & 7.4 & 7.27 \\
$\begin{array}{l}\text { Diffusion coefficient } \\
\left(\mathrm{m}^{2} / \mathrm{s}\right) \text { after }\end{array}$ & 5.4 & 5.4 & 5.6 & 5.6 & 5.2 & 5.2 & 5.37 \\
\hline
\end{tabular}

Abbreviation: TAM-KI, tamoxifen encapsulated in $\mathrm{KI}$.

Results also showed that more TAM was incorporated as additional K1 was added (Table 2). Interestingly, the more stable and more hydrophobic TBL incorporated a slightly larger amount of TAM relative to K1 $(11.3 \% \pm 2.1 \%$ greater loading), as shown in Table 2 . To provide further evidence for the incorporation of TAM into $\mathrm{K} 1$ and TBL, changes in the diffusion coefficient of TAM obtained from the DOSY NMR experiments (Tables 3 and 4) were measured and were found to vary from 7.27 to 5.37 for $\mathrm{K} 1$, and from 7.27 to 5.48 for TBL. This reduction in diffusion coefficient is indicative of an interaction between the drug and the larger RNT assemblies.

Incorporation of TAM in K1 and TBL was also investigated by UV-Vis experiments (Figure 3), which showed significantly different profiles for TAM-K1 and TAM-TBL in methanol. When the UV-Vis spectra were recorded in water, which mimics the actual physiological environment in the body, the UV-Vis profiles of K1 and TBL were significantly different from those of TAM-K1 and TAM-TBL, respectively. This result indicated once again that TAM does bind to the RNTs.

Tapping mode AFM (Figure 5) showed different heights for the aqueous solutions of RNTs in the presence and in the absence of TAM. Height measurements showed a significantly greater value for RNT-encapsulated TAM (Figure 6). The average heights were $2.91 \mathrm{~nm}, 7.40 \mathrm{~nm}, 3.02 \mathrm{~nm}$, and $6.22 \mathrm{~nm}$ for $\mathrm{K} 1$, TAM-K1, TBL, and TAM-TBL, respectively. While the values for the complexes are dramatically high relative to the uncomplexed RNTs, they do support the existence of an interaction between drug and RNTs (whose exact nature is still unknown at this stage).

\section{Discussion}

The drug-loading capacity of K1 and TBL was investigated here for the first time under various conditions using ${ }^{1} \mathrm{H}-\mathrm{NMR}$. For equivalent concentrations of TAM and RNTs, ca. $30 \%$ of the hydrophobic anticancer drug was incorporated. The amount of RNTs present was crucial to how much TAM could be loaded. Successful TAM loading was further confirmed by DOSY NMR experiments where diffusion coefficients of TAM diminished significantly after interacting with the RNTs. UV-Vis experiments supported the presence of an interaction between TAM and RNTs. Although our experiments did not establish how TAM molecules may be incorporated into the RNTs, the hypochromic effect observed in the UV-Vis spectra of TAM-TBL suggests that TAM molecules may be intercalating between the $\mathrm{G} \wedge \mathrm{C}$ bases. Furthermore, AFM height profiles showed a dramatic increase in RNT cross-section as a result of interaction with TAM. It should also be noted the RNTs maintained their structural integrity after TAM loading, which has been shown to be essential for their biological activity. ${ }^{20}$

TAM is widely used as an anticancer drug, but its water insolubility has limited its delivery and release in physiological environments. Previous studies have investigated drug delivery systems for hydrophobic drugs. ${ }^{23,24}$ A variety of water-insoluble drugs have been incorporated in biodegradable polymers, eg, poly(lactic-co-glycolic acid [PLGA]) and nonbiodegradable polymers, eg, poly(ethylene-co-vinyl acetate, EVAc). ${ }^{25,26}$ However, several issues associated with these polymers have been raised such as the presence of residual organic solvents, toxicity of photoinitiators, and complex material preparation. ${ }^{25,27}$

Table 4 DOSY NMR of TAM and of TAM-TBL mixture (5:5 molar ratio)

\begin{tabular}{|c|c|c|c|c|c|c|c|}
\hline TAM peaks & Peak I & Peak 2 & Peak 3 & Peak 4 & Peak 5 & Peak 6 & Average \\
\hline Chemical shift (ppm) & 6.7 & 6.55 & 3.9 & 3.1 & 2.58 & 2.41 & - \\
\hline $\begin{array}{l}\text { Diffusion coefficient } \\
\left(\mathrm{m}^{2} / \mathrm{s}\right) \text { before }\end{array}$ & 7.2 & 7.4 & 7.2 & 7.4 & 7.4 & 7 & 7.27 \\
\hline $\begin{array}{l}\text { Diffusion coefficient } \\
\left(\mathrm{m}^{2} / \mathrm{s}\right) \text { after }\end{array}$ & 5.3 & 5.4 & 5.6 & 5.6 & 5.6 & 5.4 & 5.48 \\
\hline
\end{tabular}

Abbreviations: TAM, tamoxifen; TAM-TBL, tamoxifen encapsulated in TBL. 

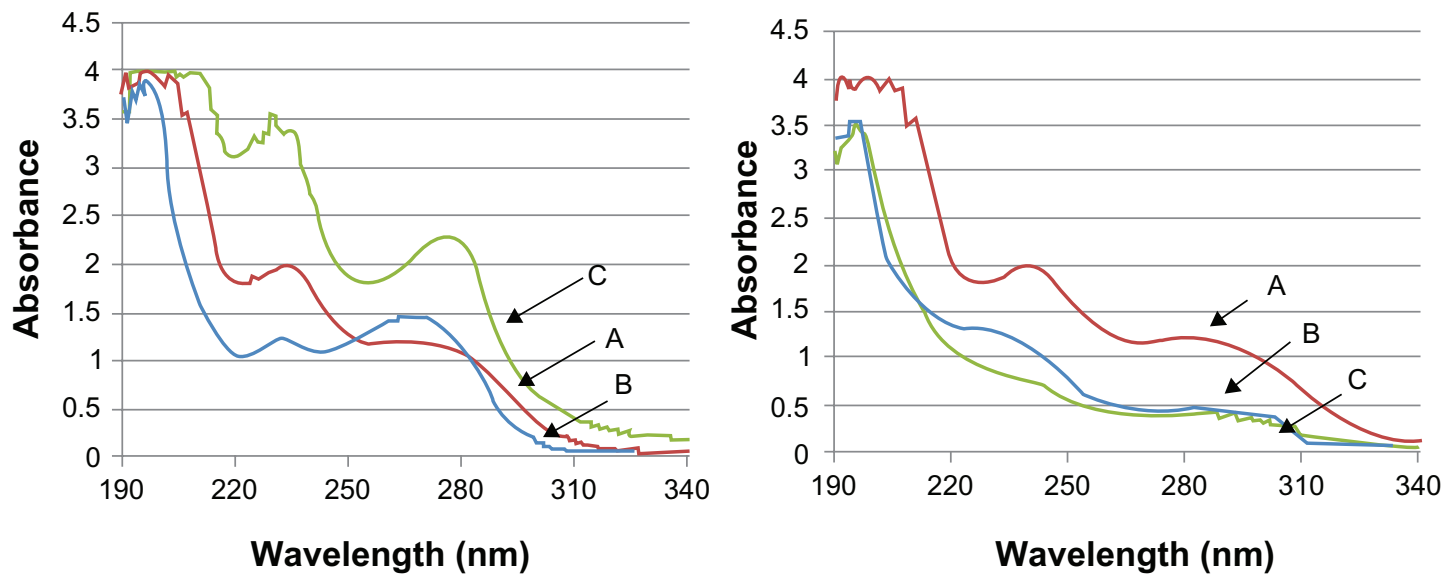

Figure 3 UV-Vis spectra recorded in methanol of A) TAM $(5 \mu \mathrm{g} / \mathrm{mL})$, B) KI (left) and TBL (right) $(25 \mu \mathrm{g} / \mathrm{mL}), \mathbf{C}) \mathrm{TAM}-\mathrm{KI}$ (left) and TAM-TBL (right) (25 $\mu \mathrm{g} / \mathrm{mL})$. Abbreviations: $\mathrm{KI}$, rosette nanotubes with lysine; TAM, tamoxifen; TAM-KI, tamoxifen encapsulated in KI; TAM-TBL, tamoxifen encapsulated in TBL.
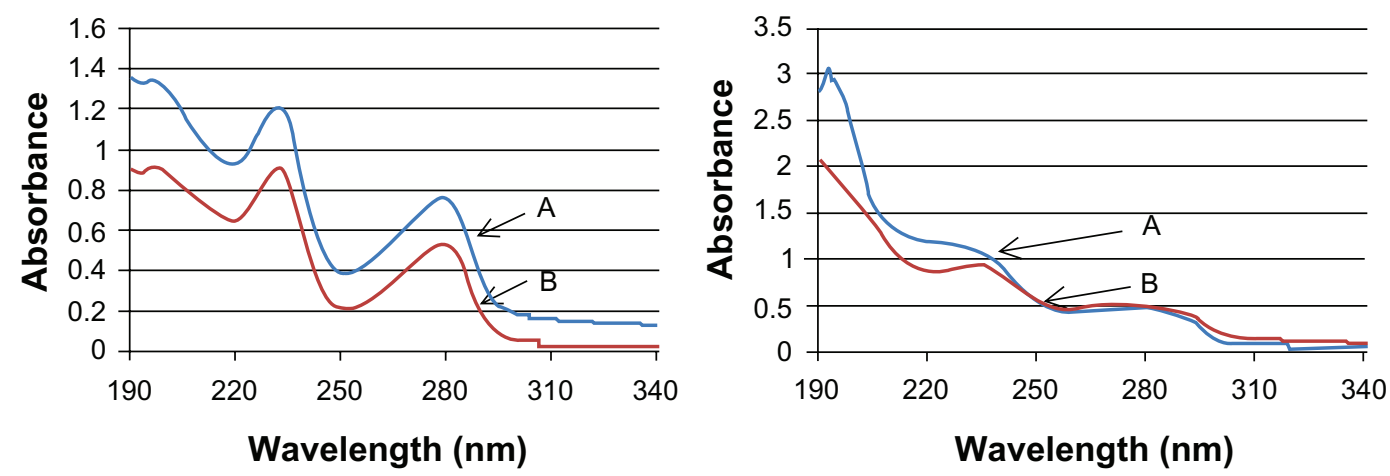

Figure 4 UV-Vis spectra recorded in water of A) TAM-KI (left) and TAM-TBL (right), and B) KI (left) and TBL (right). All samples were at a concentration of $25 \mu \mathrm{g} / \mathrm{mL}$. Abbreviations: $\mathrm{KI}$, rosette nanotubes with lysine; TAM, tamoxifen; TAM-KI, tamoxifen encapsulated in KI; TAM-TBL, tamoxifen encapsulated in TBL.
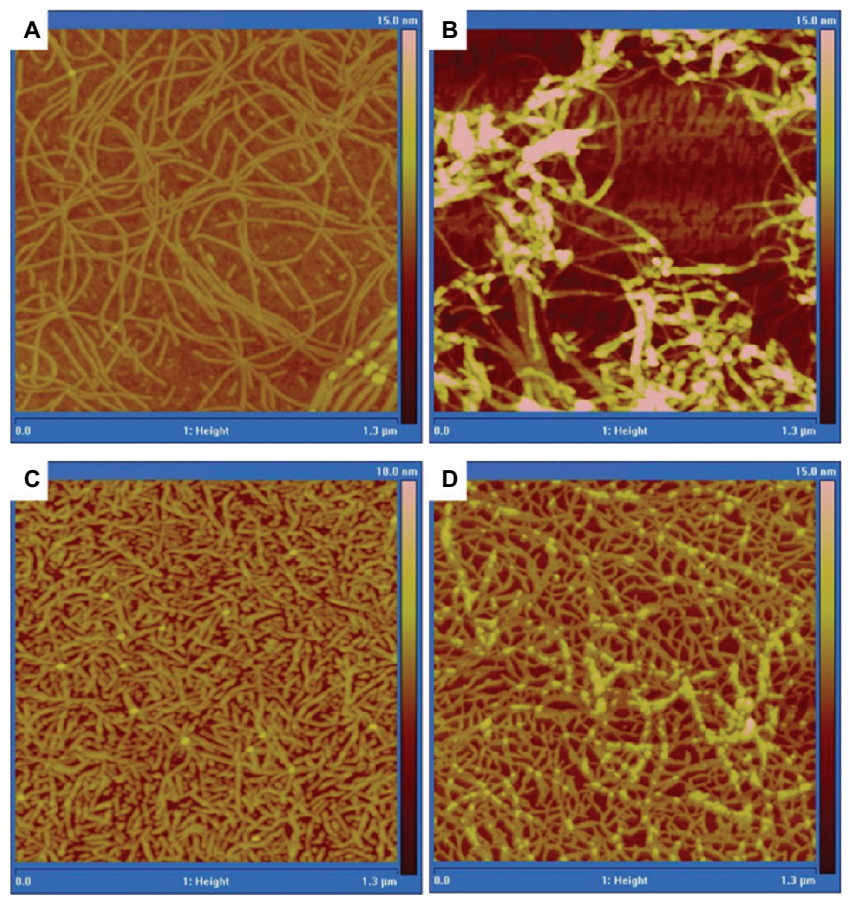

Figure 5 Tapping mode AFM height images of A) KI, B) TAM-KI, C) TBL, and D) TAM-TBL.

Abbreviations: KI, rosette nanotubes with lysine; TAM, tamoxifen; TAM-KI, tamoxifen encapsulated in KI; TAM-TBL, tamoxifen encapsulated in TBL. 


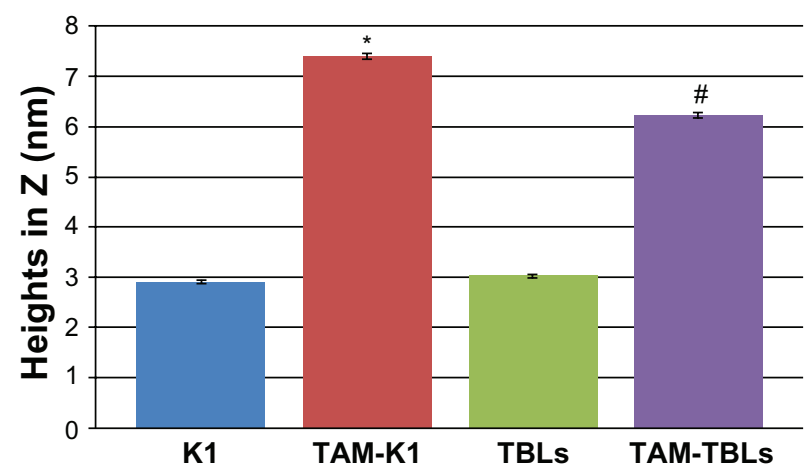

Figure 6 Quantitative height measurements by atomic force microscopy. Notes: Data are mean \pm standard error of mean (more than 30 random points were chosen from atomic force microscopy scans). $* P<0.05$ compared with $\mathrm{KI}$ only; \#P $<0.05$ compared with TBL only.

Abbreviations: $\mathrm{KI}$, rosette nanotubes with lysine; TAM, tamoxifen; TAM-KI, tamoxifen encapsulated in KI; TAM-TBLs, tamoxifen encapsulated in TBLs, TBLS, twin base linkers.

For example, PLGA is one of the most widely used drug delivery agents, but its acidic degradation byproducts (lactic acid and glycolic acid) possess some degree of cytotoxicity. ${ }^{28}$ In addition, some studies have found that the organic solvents used in the formulation of PLGA (eg, $\mathrm{CH}_{2} \mathrm{Cl}_{2}$ ), still present in trace amounts, could negatively influence surrounding cells and tissues. ${ }^{25}$

In situ injectable drug delivery systems have also received much attention. Firstly, such methods are less invasive and less painful compared with implant insertion, which requires local anesthesia and surgery. Secondly, localized or systemic drug delivery can be achieved for prolonged periods of time, typically ranging from one to several months. ${ }^{27}$ For instance, polyethylene glycol-oligo-glycolyl-acrylate can be crosslinked to encapsulate drugs using a photoinitiator such as eosin. However, such methods are restricted to the correct wavelength and the accessibility to a light source. More importantly, the potential toxicity of the photo crosslinker is another source of concern.

Therefore, compared with conventional drug delivery systems, RNTs as described here can self-assemble in situ and are water soluble, biocompatible nanomaterials, suitable for hydrophobic drug incorporation. Moreover, in the present study, TBL were introduced as a new generation of selfassembled RNTs because they have six twin $\mathrm{G} \wedge \mathrm{C}$ base units, which leads to stronger hydrogen bond networks, stronger $\pi$-stacking interactions, and as a result a more stable RNT. Although this study demonstrated the ability of RNTs to load TAM in water, we envision that several other hydrophobic drugs could be excellent candidates for encapsulation and delivery by the RNTs.

\section{Conclusions}

In summary, the relatively simple procedure described in this study to load TAM into RNTs could offer an ideal drug delivery system for hydrophobic drugs. The biocompatibility, amphiphilic nature of the RNTs solve a number of drug delivery problems, including limited water solubility and bioavailability in physiological environments. RNT-encapsulated TAM should be further studied as an anticancer coating on current implants or as stand-alone injectable drug delivery vehicle. Additional in vitro studies to study drug-release kinetics and the bioactivity of TAM after incorporation in RNTs are currently underway.

\section{Acknowledgments}

We thank Brown University International Scholar Program, the Hermann Foundation, the National Research Council of Canada, the Natural Science and Engineering Research Council of Canada, and the University of Alberta for funding this work. We also thank Dr Jae-Young Cho for recording the AFM images.

\section{Disclosure}

The authors report no conflicts of interest in this work.

\section{References}

1. Guo W, Huang K, Tang R, Xu H. Synthesis, characterization of novel injectable drug carriers and the antitumor efficacy in mice bearing sarcoma-180 tumor. J Control Release. 2005;107:513-522.

2. Guo W, Shi Z, Liang K, Chen X, Li W. Polyanhydride modified unsaturated polyesters as injectable drug carriers: Synthesis and antitumor efficacy in sarcoma-180 mice bearing tumor. Polym Degrad Stabil. 2006;91:2924-2930.

3. Guo W, Shi Z, Liang K, Liu Y, Chen X, Li W. New unsaturated polyesters as injectable drug carriers. Polym Degrad Stabil. 2007;92:407-413.

4. Kakinoki S, Taguchi T, Saito H, Tanaka J, et al. Injectable in situ forming drug delivery system for cancer chemotherapy using a novel tissue adhesive: Characterization and in vitro evaluation. Eur J Pharm Biopharm. 2007;66:383-390.

5. Okino H, Nakayama Y, Tanaka M, et al. In situ hydrogelation of photocurable gelatin and drug release. J Biomed Mater Res. 2002;59: 233-245.

6. Reddy HL, Vivek K, Bakshi N, et al. Tamoxifen citrate loaded solid lipid nanoparticles (SLN ${ }^{\mathrm{TM}}$ ): Preparation, characterization, in vitro drug release, and pharmacokinetic evaluation. Pharm Dev Technol. 2006;11: $167-177$.

7. Jones MC, Leroux JC. Polymeric micelles - a new generation of colloidal drug carriers. Eur J Pharm Biopharm. 1999;48:101-111.

8. Sharifi S, Mirzadeh H, Imani M, et al. Injectable in situ forming drug delivery system based on poly(e-caprolactone fumarate) for tamoxifen citrate delivery: Gelation characteristics, in vitro drug release and anti-cancer evaluation. Biomaterials. 2009;5:1966-1978.

9. Kwon GS, Okano T. Polymeric micelles as new drug the block copolymer, since the auxiliary agents are carriers. Adv Drug Deliv Rev. 1996; 21:107-116.

10. Kataoka K, Harada A, Nagasaki Y. Block copolymer micelles for drug delivery: Design, characterization and biological significance. Adv Drug Deliv Rev. 2001;47:113-131. 
11. Torchilin VP. Structure and design of polymeric surfactant-based drug delivery systems. J Control Release. 2001;73:137-172.

12. $\mathrm{Xu} \mathrm{C}$, Xie J, Ho D, et al. Au- $\mathrm{Fe}_{3} \mathrm{O}_{4}$ dumbbell nanoparticles as dualfunctional probes. Angew Chem Int Ed Engl. 2008;47:173-176.

13. Liu HW, Chen CH, Tsai CL, Lin IH, Hsiue GH. Heterobifunctional poly(ethylene glycol)-tethered bone morphogenetic protein-2stimulated bone marrow mesenchymal stromal cell differentiation and osteogenesis. Tissue Eng. 2007;13:1113-1124.

14. Yang L, Webster TJ. Nanotechnology controlled drug delivery for treating bone diseases. Expert Opin Drug Deliv. 2009;6:851-864.

15. Gindy ME, Prud'homme RK. Multifunctional nanoparticles for imaging, delivery and targeting in cancer therapy. Expert Opin Drug Deliv. 2009;6:865-878.

16. Chun AL, Moralez JG, Fenniri H, et al. Helical rosette nanotubes: A more effective orthopaedic implant material. Nanotechnology. 2004; 15:S234-S239.

17. Chun AL, Moralez JG, Webster TJ, et al. Helical rosette nanotubes: A biomimetic coating for orthopedics? Biomaterials. 2005;26 7304-7309.

18. Fenniri H, Mathivanan P, Vidale KL, et al. Helical rosette nanotubes: Design, self-assembly and characterization. J Am Chem Soc. 2001;123: 3854-3855.

19. Moralez JG, Raez J, Yamazaki T, et al. Helical rosette nanotubes with tunable stability and hierarchy. J Am Chem Soc. 2005;127: 8307-8309.
20. Zhang L, Rakotondradany F, Myles AJ, et al. Arginine-glycine-aspartic acid modified rosette nanotube-hydrogel composites for bone tissue engineering. Biomaterials. 2009;30:1309-1320.

21. Zhang L, Chen Y, Rodriguez J, et al. Biomimetic helical rosette nanotubes and nanocrystalline hydroxyapatite coatings on titanium for improving orthopedic implants. Int J Nanomedicine. 2008;3:323-333.

22. Macgregor J, Jordan VC. Basic guide to the mechanisms of antiestrogen action. Pharmacol Rev. 1998;50:151-196.

23. Okada H, Toguchi H. Biodegradable microspheres in drug delivery. Crit Rev Ther Drug Carrier Syst. 1995;12:1-99.

24. Fung LK, Saltzman WM. Polymeric implants for cancer chemotherapy. Adv Drug Deliv Rev. 1997;26:209-230.

25. Bitz C, Doelker E. Influence of the preparation method on residual solvents in biodegradable microspheres. Int J Pharm. 1996;131: 171-181.

26. Li S, Lepage M, Merand Y, Belanger A, Labrie F. Growth inhibition of 7,12-dimethylbenz(a)anthracene-induced rat mammary tumors by controlled-release low-dose medroxyprogesterone acetate. Breast Cancer Res Treat. 1992;24:127-137.

27. Packhaeuser CB, Schnieders J, Oster CG, Kissel T. In situ forming parenteral drug delivery systems: An overview. Eur J Pharm Biopharm. 2004;58:445-455.

28. Athanasiou KA, Niederauer GG, Agrawal CM. Sterilization, toxicity, biocompatibility and clinical applications of polylactic acid/ polyglycolicacid copolymers. Biomaterials. 1996;17:93-102.
International Journal of Nanomedicine

\section{Publish your work in this journal}

The International Journal of Nanomedicine is an international, peerreviewed journal focusing on the application of nanotechnology in diagnostics, therapeutics, and drug delivery systems throughout the biomedical field. This journal is indexed on PubMed Central, MedLine, CAS, SciSearch ${ }^{\circledR}$, Current Contents ${ }^{\circledR} /$ Clinical Medicine,

\section{Dovepress}

Journal Citation Reports/Science Edition, EMBase, Scopus and the Elsevier Bibliographic databases. The manuscript management system is completely online and includes a very quick and fair peer-review system, which is all easy to use. Visit http://www.dovepress.com/ testimonials.php to read real quotes from published authors. 